\section{Simplified procedure for the detection of antigens by crossed immunoelectrophoresis}

\author{
J. W. KEYSER AND K. LEWIS From the Department of \\ Chemical Pathology, The Welsh National School of \\ Medicine, Royal Infirmary, Cardiff
}

In testing biological fluids for specific antigens by the method of crossed immunoelectrophoresis in agar gel (Bussard, 1959; Culliford, 1964; Kohn, 1967 ) it is usually necessary to set up one or more dilutions of the test material in order to avoid false negative results due to an excess of antigen. The need for making dilutions can be obviated by the use of opposed triangular or tapered troughs (Fig. 1), which ensure a large excess of antigen at one end and of antibody at the other, with a continuous change in the proportion in between. This gives a greater range of antigen:antibody ratios than does the procedure of Kohn and Morgan (1971), which employs two wells of different size for the test serum. The sensitivity of the technique is high, since the whole of the specimen is allowed to react with antiserum, there being no portion of the specimen trough that is not in the direct path of the reverse flow of antibody.

The slide is covered with a $1-\mathrm{mm}$ layer of $1 \%$ agar in barbitone buffer of $p \mathrm{H} 8.2$, ionic strength 0.05 , Received for publication 13 September 1972.

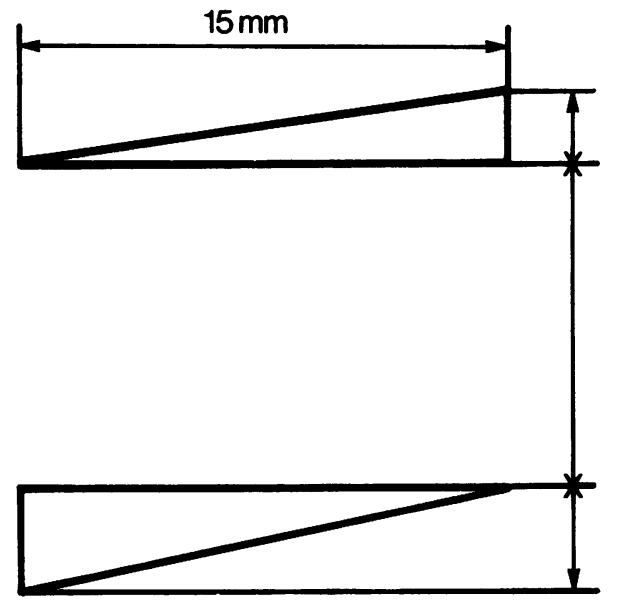

Fig. 1 Pattern of antigen (lower) and antibody troughs.

and tapered troughs are cut either with a fine scalpel or with a suitable gel punch. For a 1-mm layer of $\frac{2}{20}$ agar, the troughs shown in Fig. 1 have a capacity of about $15 \mu \mathrm{l}$ and $23 \mu \mathrm{l}$ respectively, but the dimen- $\overrightarrow{0}$ sions do not appear to be critical. Antiserum ang $\omega$ test serum respectively are diluted with one thize volume of a $1 \%$ solution of agar in the buffer, keg: molten at 40 to $45^{\circ}$, and the mixtures are rapide transferred to the appropriate troughs, where gelling occurs. Connexion with the buffer in the tank is made in the usual way with filter paper, and a

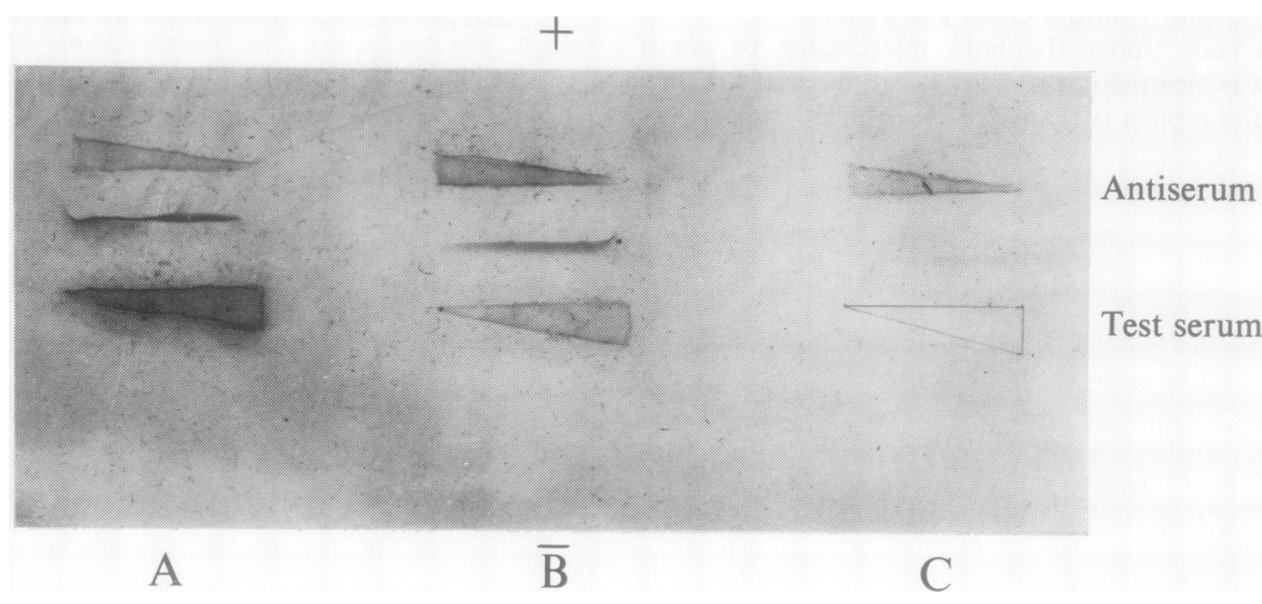

Fig. 2 Precipitin line obtained with specimen of cord blood serum and anti- $\alpha_{1}-$ fetoprotein serum. A, undiluted specimen; B, specimen diluted 1-10; C, specimen diluted 1-50. In this experiment the specimens were mixed with an equal volume of $1 \%$ agar. Stained with Coomassie Brilliant Blue. 
constant current of approximately 1.4 ma per $\mathrm{cm}$ width of agar plate is passed for a suitable time. Under these conditions $a_{1}$-fetoprotein gives visible precipitin lines within about one to two hours. The sensitivity of the test is considerably increased by subsequent staining. A positive result can be confirmed by means of a reaction of identity with a positive control (Kohn, 1970).

Figure 2 shows a reaction for $a_{1}$-fetoprotein obtained with cord blood serum. To illustrate the principle of the method two dilutions have also been tested, though routinely this would be unnecessary. Clearly, the undiluted specimen gave no reaction in the region where it was present at greatest excess, ie, at the right hand side in Fig. 2(A), whereas the 1-50 dilution gave a reaction in this region but not at the lowest concentration. (The dilutions refer to the serum before mixing with agar.) In this way, by observing the extent as well as strength of the precipitin line one is able to make a semi-quantitative assessment of the amount of antigen present.

Although we have used this modification only for detecting $\alpha_{1}$-fetoprotein, it is presumably of general applicability.

The antiserum was obtained from Nordic Pharmaceuticals and Diagnostics (Tilburg, Holland). We wish to thank Mr D. H. Brown of the Physiology Department, University College, Cardiff, for constructing the gel punch, and the Department of Medical Illustration, Cardiff Royal Infirmary, for the photographs.

References

Bussard, A. (1959). Description d'une technique combinant simultanément l'électrophorèse et la précipitation immunologique dans un gel: l'électrosynérèse. Biochim. biophys. Acta (Amst.), 31, 258-260.

Culliford, B. (1964). Precipitin reactions in forensic problems. Nature (Lond.), 201, 1092-1094.

Kohn, J. (1967). Application of immunoelectrophoretic techniques to the study of serum proteins. Symposium Series Immunobiology Standard, Vol. 4, pp. 17-24.

Kohn, J. (1970). Method for the detection and identification of alpha fetoprotein in serum. J. clin. Path., 23, 733-735.

Kohn J., and Morgan, J. R. (1971). Pitfalls of Australia antigen detection and screening. J. clin. Path., 24, 673-674.

\section{Letters to the Editor}

\section{Rubella Screening Tests}

We read with interest the article entitled 'A screen test for rubella haemagglutination-inhibition antibodies' (Thomas and Kempsell, 1972). In devising screening tests designed to save technician time it is always with regret that one accepts the necessity to repeat some of the tests, but we were surprised to read that $30 \%$ of the sera submitted to the screen test described had to be repeated in a full rubella HAI titration. The major difficulty appears to be lack of a clear-cut distinction between positive and negative sera at the dilution tested (1 in 32). A minor difficulty, but one which would be much more significant for anyone, like ourselves, who use pigeon RBCs, is the interference in the test of non-specific haemagglutinins. Our own screening test minimizes both difficulties, and is based on the following background observations.

Using the rubella haemagglutinin currently available from either Flow Laboratories Inc, Irvine, Ayrshire, or The
Standards Laboratory, Central Public Health Laboratory, London, NW9 5HT, the removal of non-specific inhibitors of rubella-virus haemagglutination by kaolin according to the method of Halonen, Ryan, and Stewart (1967) is virtually instantaneous and is unaffected by the presence of pigeon $\mathrm{RBC}$ up to a final concentration of $3 \%$. Moreover such a concentration of pigeon cells will remove the non-specific haemagglutinins of a 1 in 10 dilution of the vast majority of sera within $20 \mathrm{~min}$, and this removal is marginally more effective in the presence of $12.5 \%$ kaolin. $\mathrm{MnCl}_{2} /$ heparin pretreatment is not used since in an HAI test involving overnight preincubation of virus/serum mixtures (see below) false positives are occasionally found with some antigens, and such pretreatment will always involve an extra step of further diluting the pretreated supernatants before placing in the microtitre wells.

Having pretreated sera with kaolin and pigeon RBCs the rubella HAI titres are determined in a microtitre system involving the mixtures of 4 units of haemagglutinin with serial doubling dilutions of serum using $0.4 \%$ bovalbuminborate-saline pH $9 \cdot 0$ (Clarke and Casals, 1958) as both antigen and serum diluent.
Virus/serum mixtures are then preing cubated overnight prior to the addition of $0.25 \%$ pigeon RBCs in the RBC diluent of Stewart, Parkman, Hopps, Douglas, Hamilton, and Meyer (1967). Tests are then incubated at $4^{\circ} \mathrm{C}$ for one hr and read after 20 min standing at room temperature. The long preincubation period of virus/serum mixtures improves the distinction between positive and negative sera (see fig.).

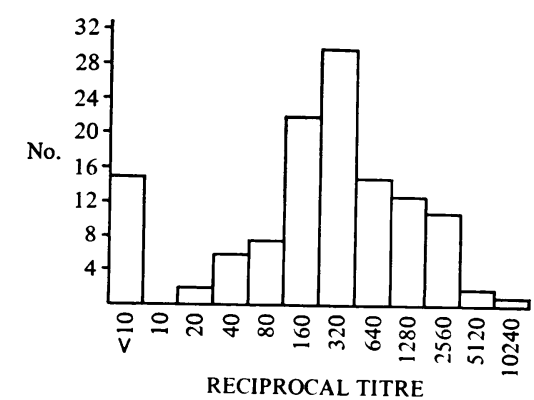

Fig. Distribution of rubella HAI titres of 125 sera selected at random from those submitted from the antenatal clinic for screening. 